\title{
The Study of Women Dress in Zhang Daqian Beauty Paintings
}

\author{
Liu Yang \\ School of Art \\ Panzhihua University \\ Panzhihua, China
}

\author{
Long Jiang \\ School of Art \\ Panzhihua University \\ Panzhihua, China
}

\begin{abstract}
This paper analyses the Zhang Daqian paintings of women dress from the perspective of the history of clothing and clothing aesthetics, and it extracts the specific description of female dress and classifies it. Then it explores Zhang Daqian beauty paintings of women dress in clothing, hairstyles, headwear and face and so on with women dress history in various dynasties as a reference. Thereby it can have a deep understanding of the influence of Zhang Daqian's aesthetic taste, value orientation and spiritual world of on his description of women dress.
\end{abstract}

Keywords-Zhang Daqian; beauty paintings; women dress; classification; aesthetic

\section{INTRODUCTION}

Zhang Daqian is a rare versatile painter in the history of our country. Voted as "the first painter in contemporary world" by International Academy of Arts, he not only is good at Xieyi but does well in traditional Chinese realistic painting, landscapes, figures, flowers and birds. $\mathrm{He}$ is praised as "the well-known daqian in the five hundred years" by Xu Beihong. Daqian's famous theme is the painting of beauties, profound scholars and lotus, especially beauty paintings, showing a kind of natural, cultural and aesthetic characteristic, among which the beauty painting that he painted after returning from Dunhuang is excellent. Throughout the creation style of Daqian's beauty paintings, Taiwan scholar Zhu Jieying generalized them into three words, posture inTang dynasty, mien in Song dynasty and charm in Qing dynasty. Many paintings among these derived from intimate contact in Daqian's real life and unforgettable sentiment of missing. This paper starts from the perspective to explore Mr. Daqian's different themes of the characteristics in female dress paintings to understand Zhang Daqian's unique aesthetic about women better.

\section{DEFINITION OF FEMALE DRESS}

It is well known that, the theme of Guanyin appears in Mr. Daqian's Painting of Beauties repeatedly accounting for a large quantity, which can be said the most prominent, the most intriguing topic, for instance, Water and Moon Guanyin, Guanyin in White, Guanyin Holding Willow, Guanyin in Bamboo Forest. However, the origin of Guanyin Bodhisattva, the Great Bodhisattva, is male, and it can be a male or a female in terms of its category. For example,
Guanyin is described in Avatamsaka Sutra as "brave man." Prior to Tang Dynasty, Guanyin appears as a male in most cases, and in some cases, also appears as a female. But later, especially since the legendary Miaoshan Princess, the image of Guanyin in Han region is more and more feminine, for example, the 33 images of Guanyin that spreading among the people are all females. Some scholars directly call Guanyin as the Eastern goddess [1]. Therefore, this paper also refers Guanyin as a female.

Dress is short for clothing and making up. In particular, it refers to the beauties' clothing and appearance, including facial makeup, hair style, headware, shoes, etc. All the forms or objects that can make body decoration are all the objects to be studies in this paper.

There are plentiful subject matters of Mr. Daqian's Painting of Beauties. Some scholars divide Mr. Daqian's Painting of Beauties into four categories according their subject matters: first, the outstanding women in history, such as Yang Guifei, Hong Fu Nv, Wang Zhaojun, Su Xiaoxiao, etc; second, the goddesses in ancient myths and legends, such as Madame Xiang, Nv Wa, Chang'e, Fairy Lingbo, Fairy Peach; Third, the feminine Bodhisattva and heavenly maids, such as various images of Guanyin, the heavenly maids scattering blossoms and so on; fourth, female characters in our life [2]. This is classified pursuant to the subject matters of the painting, which is not suitable for the research thought of this paper. Therefore, Mr. Daqian's Painting of Beauties is divided into three categories in this paper according to the differences of female dress: first, painting of beauties who are in ancient costume, referring to the females who are dressed in ancient costume, including prominent women in history, fairies in myths and legends, and all kinds of Guanyin Bodhisattvas and ordinary women, which account for a large proportion in Mr. Daqian's Painting of Beauties. Second, painting of beauties in fashionable dress, which refers to the female dress that was popular in the times that Mr. Daqian was living and these painting were created. Third, exotic female dress, which refers to the dress that appeared in the countries that Mr. Daqian had visited and lived for many times, and the clothing and making up that were quite different from that traditional and modern Chinese female. This paper will compare and research the female dress painted by Mr. Daqian from these three kinds of categories. 


\section{CHARACTERISTICS OF THE THREE KINDS OF FEMALE} DRESSES

\section{A. Female dressed in ancient costume}

Mr. Daqian digested the paints of beauties of each dynasty after he understood the figure painting history of China thoroughly, and integrated their advantages into one as his own. After copying at Dunhuang, Zhang Daqian changed the situation of sluggish and meticulous figure painting of early Song Dynasty, Yuan Dynasty, and Ming Dynasty. The luxuriant yet fresh and elegant figure painting style was formed gradually through his sorting and mining of traditional painting, achieving the learning and transformation of tradition successfully. The females dressed in ancient costume account for a large part of $\mathrm{Mr}$. Daqian's painting of beauties, mainly concentrating the female dresses of Tang, Song, and Ming and Qing dynasties.

The female dresses in Tang Dynasty of Daqian's female dress are very characteristic, which are divided into Bodhisattva in Tang Dynasty copied by Mr. Daqian at Dunhuang, as well as Flying Apsaras, Sacrifice Providers and the general beauties of Tang Dynasty. The Bodhisattva dress popularized in Dunhuang frescoes of Tang Dynasty is mainly influenced by the Buddhist Art of China's Xinjiang region. The dresses of Bodhisattva copied by Mr. Daqian are the long skirts of thin silk with veil of noble women in Tang Dynasty. The styles of the skirts are diverse, including the Red Skirt, white silk skirt and brocade skirt, which are mostly the new style of Chinese brocade skirt with outer waist skirt. The upper garment of Bodhisattva mainly includes winding axillary, monk clothes, scarf, and large square shawl and so on. The Bodhisattva is plump and smooth-skinned with tender bone as well as rich and colorful bearing, having crown with jewels, sun and moon crown, Buddha crown, flower crown, moire crown, leaf crown and so on. The wreaths with the function of supporting and decoration are made up of various jades with two forms of long and short. The short wreath is mostly necklace-typed or made up of beads; the long wreaths are divided into the lateen long wreath, X-typed and U-typed ones. The eyebrow types of Bodhisattva are mostly long and thin and mostly are bright green and deep black; Bodhisattva's lip is petite, round, mellow and bright, having obvious characteristics of the times, which is consistent with the popular makeup. The soul of Flying Apsaras art lies in "flying". As a result, even though the majority of Flying Apsaras art shirtless and their elegant posture can fully demonstrate the women's curvy beauty; the sense of lightness and flying can only be reflected by virtue of the graceful long dress, super-long shawl, as well as the winding axillary, monk cloth and skirts. Hair types of Flying Apsaras mainly include the several popular female buns such as high bun with crown, vertical bun, birdshipped bun and cloud-shaped bun. The wreaths of Flying Apsaras are mainly presented as the short form. In early Tang Dynasty, the eyebrow of Flying Apsaras was thin and long, and at flourishing Tang Dynasty, it was thick and long, and at middle and late Tang Dynasty, it returned to thin and long. The lip Flying Apsaras is the petite plump red lips. The clothing of female providers in Dunhuang frescoes not only has the general clothing culture of Tang Dynasty, but also reflects the aesthetic features after integration of Western regional culture and civilization of Central Plains. Therefore, the dresses of both female providers and general beauties in Tang Dynasty are analyzed together in this paper. Evening neck -typed clothes are commonly seen in the clothing of female provider and general beauties, which can be divided into U-shaped and $\mathrm{V}$-shaped ones, baring more of their neck and chest, which has a close relationship with the liberal politics and thought in Tang Dynasty. It is the classical female dress image in Tang Dynasty of high waist skirt with scarf, and the combined collar, double-breasted half-arm shawl with belt in from is often dressed in addition to the jacket. On important occasions, the full sleeve-typed jacket is required, which is in the form of formal dress: jacket, long dress, and the double-breasted full sleeve-typed shirt. Female dressed as male is also popular in the Tang Dynasty, such as "Recent Matters and People" describes that wearing male round collar-typed shirt with soft waist belt is the popular female dress in Tang Dynasty. The hair type of female providers in Dunhuang frescoes is basically high bun. Those common ones include mountain-typed bun, cloud-typed bun, spiral-typed bun, anti-coil bun, double ring-typed bun, and $\mathrm{Wu}$ Man bun, etc. [3]. In the general painting of beauties in Tang Dynasty, their hair style is mostly cloud-shaped bun, for example, Guifen's bun in the painting of Yang Fei Playing with the Parrot. The gold hairpin and jewelrys are most decorated on the bun, playing the role of fixing and decoration and aesthetic. The eyebrow style of women in Tang Dynasty has rich forms and different styles. Generally speaking, it can be divided into two types of thick and thin. However, in Mr. Daqian's painting of beauties, their eyebrows are all thin and long no matter they are in early, flourishing or late Tang Dynasty, for example, the willow-lean eyebrows and crescent-shaped eyebrows, which is related to the author's preferences. The females in Mr. Daqian's paintings of beauties in the Tang Dynasty all have "cherry-shaped small mouth", which is closely related to the Point Lip in Tang Dynasty.

Female's dress in the Song Dynasty can be seen at a glance in the two paintings "Makeup Picture" by $\mathrm{Mr}$. Daqian in 1945, where two ladies have the same gesture, picture structure and clothing styles, but the difference of clothing veins and decorations. The ladies wear gilet and Ruqun skirt. The female in the Song Dynasty wear straightcollar double-breasted style gilet with tight sleeves, and the front of the gilet is mostly added with decorations of different color from the gilet. Inside, there is underdress covering the chest and abdomen. The ladies are combing hairs and arranging their headband, with jade ring and silk sash around in their waist. The female dressing in the Ming Dynasty is mainly the rightward cross-collar Ruqun skirt of phoenix-tail style of pleated style, and the straight-collar gilet with small sleeves, while the gilet with large sleeves is mostly provided for noblewomen, as well as the elbow-style small boots. The gilet at this time is slightly longer than that in the Song Dynasty. Bijia (sleeveless over-dress) is also popular in the Ming Dynasty, longer than the gilet, with hem beyond the knee, and it is mostly made of bright and beautiful silks and sometimes is also filled with cotton, used 
in the season just turns warm, such as a copy of ladies by the painters in the Qing Dynasty. After the Qing Dynasty, Mr. Daqian had never painted Manchu women, but Han Chinese women dressing in the Qing Dynasty. The dressing is similar for Han Chinese ladies in the the late Ming and the early Qing Dynasty, and the Chinese female coat skirts (short coat and long skirt) with strong decorations embroideries and also dress smock appeared in the late Qing Dynasty, of which the long skirt is mostly under the long coat. In 1956, Mr. Daqian provided cover illustration for Zhang Xinhai's A Torn Lily or Flower in the Vicious Sea in US version. Sai Jinhua has the same gesture with that in the Painting of Imperial Concubine Yang Playing Parrot, but the dressing is changed into that for Han Chinese female in the late Qing Dynasty. The upper is rightward lapel coat with inverted sleeves, and the collar, front of coat, cuff and both vents have embroidered edges and decorations, happen to meet the popular eighteen embroidered border at that time, while the embroidered border is a major feature of female dressing in the Qing Dynasty. Simple and neat hair chignon is arranged with beautiful and shining headwear, becoming a typical dressing of Han Chinese female in the late Qing Dynasty.

\section{B. Fashionable dress of women}

Traditional Chinese paintings of beautiful women of Mr. Daqian mainly include women with ancient costume as well as fashionable and sexy women, especially Portrait of Modern Lady made in 1945. It is the typical dressing of modern beauty with cheongsam in the 1930s. She has big wave hair, deep red lips and delicate eyes and brows and wears sleeveless long cheongsam with plain color. The collar, gussets and hemline are decorated with light blue edging. She wears high heels sandal with her toes outside and bracelet, reclines the plantain and sits on the ground. The underwear is exposed in the side of the cheongsam but she is not shy and thought to be sexy. No wonder $\mathrm{Xu}$ Jianrong sees the painting and says, "The lady is glamorous, with beautiful face, natural and unrestrained posture, full of vigor. It is a feast for the eyes, even lets people feel transported". Most protagonists on traditional Chinese paintings of beautiful women of Mr. Daqian after the 1950s have shown aesthetic quality of modern women. They are infinitely affectionate, beautiful and graceful, delicate and unrestrained as well as charming. These beautiful ladies are modern and open, instead of being implicit, conservative and shy.

\section{Exotic female dressing}

On the journey, Mr. Daqian encounters many exotic ladies. These beautiful and unique ladies are brought in his paintings. He develops a school of his own. These paintings have immeasurable artistic value in his artistic career. In July 1943, on the way of returning from Dunhuang to Sichuan, Mr. Daqian encountered two Tibetan women with black Tibetan Mastiffs on a lash, but they did not allow Mr. Daqian to draw them face to face. At the beginning of 1944, Daqian drew Two Tibetan Women with Black Tibetan Mastiffs. In the painting, Tibetan beauties with gorgeous clothing stand vividly revealed on the paper. They have long hair, wear fur hat, and dark red robe with fur decorated on collar and sleeves. The right shoulder is outside the robe, with right gusset dropping down, spanner band around the waist, white crossed collar unlined clothes inside the robe, red coral and kallaite necklace on the neck. A black fierce Tibetan mastiff lies beside them. Afterwards, Daqian drew a few works of Tibetan Women Control Tibetan Mastiff and displayed some of them in Cernuschi Gallery of Paris in 1946. After that, Daqian did not draw with Tibetan women as the theme.

After migrating to Darjeeling of India in 1950, Daqian drew many traditional Chinese paintings of beautiful Indian women, describing life of Indian women, such as dancing, drawing water and feeding goose, etc. When Ye Qianyu visited Mr. Daqian in 1945, Daqian drew Dancing Lady, Dance of Dedicating Flowers and Tianmo Dance according to Indian dance of Ye Qianyu. Indian ladies on paintings of Daqian wear traditional Indian sari, matching with petticoat and little doublet. The color of sari is bold and brightcolored. Except for single colors such as peach, bright orange, fired red and sapphire blue, it also has various traditional patterns. The design of sari reveals difference among chest, waist and haunch, which makes the ladies more enchanting and sexy. They are healthy and nice in dancing and life. Most beautiful Indian women have the hair worn in a bun or just let the hair fall. They have black and long eyebrows and pay attention to decoration of eyes, with a red dot on their forehead. Bracelet, necklace and anklet are necessary ornaments of them, as if we can hear silvery sound when they walk and dance.

Mr. Daqian once went to Japan to buy writing brush, ink stick, ink slab and paper and stayed for a long time beside famous Ueno Park. He loved Miss Yamada very much, who took care of his life at that time. Therefore, several painting texts of Miss Yamada were created and witnessed the love story between them. Among traditional Chinese paintings of beautiful women of Mr. Daqian, the painting text of Miss Yamada is the most romantic and thought-provoking. Daqian never published these painting texts all his life. But the portrayal of soft and enchanting Japanese woman completely and clearly records the love between the painter and model.

\section{Aesthetic Cause of Dressing of Beautiful Women Painted by Daqian}

In modern times, the national power of China is weak. Characters drawn by painters, especially beauties are weak and slender. Most of them are morbid beauties like Lin Daiyu. Mr. Daqian returned from Dunhuang. Women in his paintings are healthy and nice. It has certain relationship with plump, strong and tall women in Dunhuang Frescoes. The new technique of painting beauties will inevitably have a new impact on modern painting circle.

Mr. Daqian also pays close attention to draw lifelike characters. He thinks the key lies in the place of pupils. That is to say, the direction of sight line of people shall aim at the appreciators. Therefore, women in his paintings look around charmingly. It seems as if they are looking at you affectionately from any angle. It embodies modern and open feminine charm and reflects modern spirit and classical 
feelings of the painter. The reasons why Zhang Daqian can show spiritual temperament of modern people with traditional painting and shape vivid figures are that on one hand he can accurately feel and grasp the way that ancient people experience nature. Mr. Daqian was born in declining official family. He began to learn to read when he was six years old. Deeply influenced by traditional painting of manof-letters, he attaches importance to learning perspectives and methods that the ancients experienced nature. He once said, "The main points of painting can be summarized as learning from the ancients and the outside world and pursuing original creation". ${ }^{[4]}$ Therefore, the transformation of traditional painting of him is a creative inheritance to a larger extent. On the other hand, he can experience life deeply and paint from nature. He traveled well-known mountains and rivers even sceneries of foreign countries. People encountered by him became protagonists of his painting, such as minority women, modern girl, opera figures and modern citizens, etc. So he deeply knows the demands of the public and integrates spirit of modern people on the basis of creative inheritance of traditional painting.

\section{CONCLUSION}

French philosopher Taine once said, "The production of works depends on spirit of the time and surrounding customs". As product of the age, traditional Chinese paintings of beautiful women of Zhang Daqian will inevitably embody appearance of the age and reflect unique aesthetic features of Mr. Daqian. The spread of painting of beautiful women created by Daqian provides initiative material for contemporary people to understand aesthetic standard of Mr. Daqian for women. Women on paintings have soft contour of breast, gentle and kind eyebrows and eyes, soft, exquisite and vivid hands and magnificent clothes and show beauty and fashion that only belong to them at that time.

\section{REFERENCES}

[1] Wang Wan. Get Close to the Goddess of Mercy and Experience Easiness [M], Beijing: Baijia Press, 2011

[2] Zhu Jieying. Heritage of Beautiful Painting Text - Traditional Chinese Painting Volume of Beautiful Women of Zhang Daqian [M], Beijing: Beijing Normal University Press, 2009

[3] Zhang Xiaoping. Art of Hair Decorations of Women in Traditional Chinese Porcelain Painting of Beautiful Women in Tang Dynasty [J], Jiangsu Ceramics, 2010, 08

[4] Chen Zhidong. Discussion on Art Record of Zhang Daqian [J], Zhengzhou: Henan Fine Arts Publishing House, 2007. 